\title{
Durability and safety of David V valve-sparing root replacement in acute type $A$ aortic dissection
}

Joshua M. Rosenblum, MD, PhD, ${ }^{a}$ Bradley G. Leshnower, MD, ${ }^{a}$ Rena C. Moon, MPH, ${ }^{b}$

Yi Lasanajak, PhD, ${ }^{\mathrm{b}}$ Jose Binongo, PhD, ${ }^{\mathrm{b}}$ LaRonica McPherson, RN, ${ }^{\mathrm{a}}$ and Edward P. Chen, MD

\section{ABSTRACT}

Background: Valve-sparing root replacement (VSRR) is an attractive option in type A aortic dissection (TAAD) repair for a young patient with normal cusp anatomy, but conventional root replacement using a composite valved-conduit (ROOT) remains the gold standard in this emergent clinical setting. We examine the long-term safety and durability of the David V VSRR compared with ROOT in TAAD repair.

Methods: From March 2004 to April 2017, 136 patients underwent repair of acute TAAD using either ROOT $(n=77 ; 56.6 \%)$ or VSRR $(n=59 ; 43.4 \%)$. Annual echocardiograms were performed for follow-up in VSRR patients. Univariable regression, Kaplan-Meier, and competing risk analyses were performed.

Results: Preoperative characteristics were similar between groups, except that VSRR patients were younger (mean age $43.5 \pm 11.4$ years VSRR vs $50.4 \pm 3.0$ years ROOT; $P=.001$ ). Both groups had similar rates of preoperative malperfusion or shock ( $29.3 \%$ VSRR vs $37.0 \%$ ROOT; $P=.35$ ) and $\geq 3+$ aortic insufficiency ( $63 \%$ VSRR vs $76.8 \%$ ROOT). Thirty-day mortality in the VSRR group was $2 / 59(3.4 \%)$ and $11 / 77$ in the ROOT group $(14.3 \% ; P<.001)$. All-cause survival at 9 years was $92 \%$ (VSRR) and 59\% (ROOT; $P=.002$ ). The incidence of aortic reintervention was similar between groups $(20 \%-23 \%$ at 5 years; $P=.81)$. At 9 years of follow-up, $5 / 52(9.6 \%)$ VSRR patients had $\geq 2+$ aortic insufficiency, and 1 patient required valve reintervention.

Conclusions: In highly-selected patients, the David V VSRR provides a safe repair of acute TAAD with concomitant root pathology and valve insufficiency. In our center, the incidence of valve-related reintervention at long-term follow-up is low after emergent repair. (J Thorac Cardiovasc Surg 2019;157:14-23)

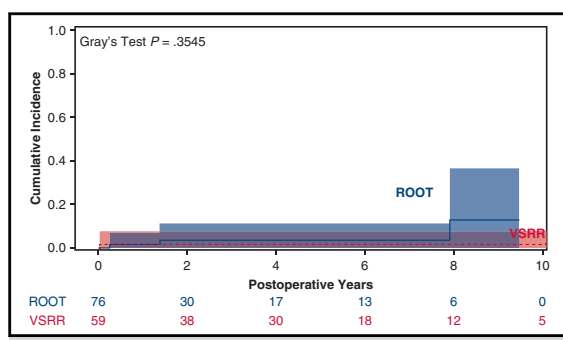

Incidence of aortic valve reintervention in VSRR and ROOT patients.

Central Message
In appropriately selected patients at high-
volume centers with aortic surgical expertise,
valve-sparing root replacement is a durable,
safe option for acute type A dissection with
root involvement.
Perspective
The gold standard surgical management in the
setting of acute type A aortic dissection with
root involvement is a Bentall procedure;
however, mounting evidence suggests that in
appropriately selected patients, valve-sparing
root replacement might be an alternative
option. The technical challenge of VSRR in
the acute setting requires extensive experience
in elective VSRR.

See Editorial Commentary page 24.
Acute type A aortic dissection (TAAD) is a surgical emergency with a primary objective of patient survival. Operative intervention is aimed at eliminating the primary intimal tear, obliterating the false lumen to restore distal true lumen perfusion, and performing any adjunct procedures that might help limit future needs for reintervention

From the a Division of Cardiac Surgery, Department of Surgery, Emory University School of Medicine, Atlanta, Ga; and ${ }^{\mathrm{b}}$ Department of Biostatistics, Rollins School of Public Health, Emory University, Atlanta, Ga.

Read at The American Association for Thoracic Surgery Aortic Symposium 2018, New York, New York, April 26-27, 2018.

Received for publication May 2, 2018; revisions received Sept 20, 2018; accepted for publication Oct 1, 2018.

Address for reprints: Joshua M. Rosenblum, MD, PhD, The Emory Clinic, 5665 Peachtree Dunwoody Rd, Suite 200, Atlanta, GA 30342 (E-mail: jrosenblum@ emory.edu)

$0022-5223 / \$ 36.00$

Copyright (c) 2018 by The American Association for Thoracic Surgery

https://doi.org/10.1016/j.jtcvs.2018.10.059 on the root or aortic valve. Initial reports of surgical repair for acute TAAD carried a $28 \%$ to $58 \%$ rate of mortality, ${ }^{1,2}$ and despite improvements in diagnostic speed, operative techniques, circulation management, and cerebral perfusion, contemporary series still report $10 \%$ to $18 \%$ surgical mortality. ${ }^{3-7}$ In most centers, replacement of the ascending aorta and hemiarch along with valve resuspension and reconstruction of the sinotubular junction with Teflon felt has resulted in satisfactory

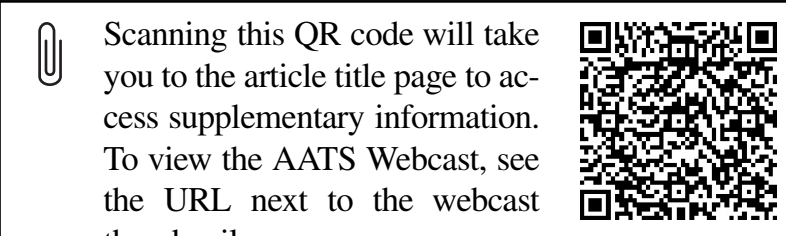
thumbnail. 


\section{Abbreviations and Acronyms \\ $\mathrm{AI}=$ aortic insufficiency \\ $\mathrm{CI}=$ confidence interval \\ ROOT $=$ aortic root replacement with composite valved-conduit \\ TAAD $=$ type A aortic dissection \\ TEE $=$ transesophageal echocardiography \\ TTE $=$ transthoracic echocardiogram \\ $\mathrm{VSRR}=$ valve-sparing root replacement}

operative outcomes with low rates of proximal aorta reintervention. ${ }^{89}$ When TAAD involves the aortic root with concomitant valve dysfunction, operative repair becomes more challenging. When root repair with valve resuspension is not feasible, conventional root replacement ("Bentall") has become the operative approach of choice, using either mechanical, stented bioprosthetic, or stentless porcine composite valved-conduits.

Drawbacks to the Bentall are related to the valve prosthesis. These include the need for lifelong anticoagulation for mechanical valved-conduits and the need for repeat valve intervention because of bioprosthetic valve degradation, especially in young patients. In the elective setting for aortic root pathology with aortic valve insufficiency, the David reimplantation ${ }^{10}$ and Yacoub remodeling ${ }^{11}$ valve-sparing root replacement (VSRR) techniques are attractive options to preserve native valve function, but carry increased myocardial ischemia time and operative complexity compared with conventional root replacement. As such, controversy exists as to whether the increased risk of VSRR should be added to the baseline high mortality of patients who undergo emergent surgery for acute TAAD.

In a previous report, we showed mid-term outcomes in patients who underwent David V VSRR in TAAD,${ }^{12}$ which have been supported by others showing no increase in mortality and durable short- and mid-term valve function. ${ }^{13-16}$ This report adds to our previous data by examining the long-term safety and durability of David V reimplantation VSRR in acute TAAD compared with patients who underwent standard Bentall aortic root replacement (ROOT).

\section{METHODS}

The Emory University (Atlanta, Ga) institutional review board approved the study, which was conducted in compliance with Health Insurance Portability and Accountability Act regulations and the Declaration of Helsinki. Because of the retrospective nature of the study, the need for individual patient consent was waived.

\section{Patients}

We evaluated records from all patients who presented to Emory University hospitals with acute TAADs from March 2004 through May 2017. A total of 603 patients underwent TAAD repair during the study period and were evaluated for inclusion in the study. Patients without root involvement and valve insufficiency, those with previous aortic valve replacements, and those who were ultimately deemed intraoperatively to have chronic dissections were excluded. A total of $136(22.6 \%)$ patients underwent emergent repair of acute TAAD with root involvement and valvular pathology necessitating intervention. Of these, $59(43 \%)$ received VSRR using the David V reimplantation technique, and $77(57 \%)$ underwent ROOT.

Initial diagnosis of acute dissection was on the basis of history, physical examination, and review of cross-sectional imaging or transesophageal echocardiography (TEE). Before skin incision, all patients had intraoperative TEE performed specifically to evaluate the root complex and the aortic valve. Cusp characteristics that excluded patients from VSRR included free margin thickening or calcification. The presence and degree of aortic insufficiency (AI) were noted, with careful attention paid to the eccentricity of the regurgitant flow. Because of the potential for asymmetric disruption of the commissural posts, an eccentric jet of AI did not necessarily represent a contraindication to VSRR. The presence of significant aneurysmal dilatation of the root $(>4.5 \mathrm{~cm}$ or $>4 \mathrm{~cm}$ with family or personal history of connective tissue disorder at the sinus segment) or irreparable destruction of the root complex secondary to aortic dissection were indications for root replacement. ${ }^{17}$ Intraoperative direct inspection of the valve cusps and hemodynamic condition of the patient guided the final decision to proceed with VSRR at the operating surgeon's discretion. Dissection in the sinus segments and behind the commissural posts in the presence of normal valve cusps was not a contraindication to VSRR. In general, VSRR was not undertaken for patients older than 65 years, those with severe or irreversible malperfusion, hemodynamic instability or shock, and those with significant preexisting medical conditions. In this series, $82 \%$ of VSRRs were performed by 2 surgeons (E.P.C and B.G.L.) whereas ROOT operations were performed by all surgeons in the group.

\section{Surgical Technique}

All patients had transcutaneous cerebral oximetry (INVOS 3100-SD; Troy, Mich) and continuous electroencephalographic monitoring, and all procedures were performed through median sternotomy with cardiopulmonary bypass. Cannulation strategy was at the discretion of the operating surgeon on the basis of extent of the anticipated aortic reconstruction, and we have previously described our cerebral protection strategy during arch reconstruction. ${ }^{18}$ Briefly, our institutional approach was to perform right axillary artery cannulation for unilateral antegrade cerebral perfusion during hypothermic circulatory arrest. Because of changes in practice patterns, some patients early in the series had retrograde cerebral perfusion with deep hypothermia as their mode of cerebral protection during circulatory arrest. At the surgeon's discretion, on the basis of patient age, renal function, expected duration of hypothermic circulatory arrest, and complexity and extent of arch reconstruction, patients were cooled to bladder temperatures of $18^{\circ} \mathrm{C}$ to $31.5^{\circ} \mathrm{C}$.

After arch reconstruction, cardiopulmonary bypass was reinitiated and rewarming began with attention turned to the aortic root and aortic valve. Coronary buttons were dissected free and mobilized after resection of all abnormal or dissected sinus tissue, leaving a 4- to 5-mm rim along the annulus. Next, the aortic valve cusps were carefully inspected for calcification, perforations or fenestrations, free margin elongation, or prolapse, which might preclude VSRR. In this particular setting, we believe that extensive cusp repair represents a contraindication to VSRR. We have previously described the details of the Emory approach to the David V VSRR. ${ }^{12,19}$ Although the technical details of valve reconstruction for VSRR do not differ between elective and acute cases, the challenge of dealing with the separated layers of the adventitia and intima during dissection of the aortic root is unique to emergent type A dissection cases. In brief, the David-Feindel formula (graft diameter $=[2 \times($ cusp height $\times 2 / 3)]+6-10 \mathrm{~mm})$ was used to determine the aortic graft prosthesis diameter, which were mostly tailored 
TABLE 1. Preoperative variables according to group

\begin{tabular}{|c|c|c|c|c|}
\hline Variable & All $(\mathbf{N}=136)$ & $\operatorname{VSRR}(\mathbf{n}=59)$ & $\operatorname{ROOT}(\mathbf{n}=77)$ & $P$ value \\
\hline Age, $y$ & $47.4 \pm 12.7$ & $43.5 \pm 11.4$ & $50.4 \pm 13.0$ & $.001^{*}$ \\
\hline Female sex & $26(19.2)$ & $9(15.3)$ & $17(22.1)$ & $.32 \dagger$ \\
\hline White race & $46(44.2)$ & $20(45.5)$ & $26(43.3)$ & $.83 \dagger$ \\
\hline Previous CAB & $4(2.9)$ & 0 & $4(5.2)$ & $.13 \ddagger$ \\
\hline $\begin{array}{l}\text { Status } \\
\text { Urgent } \\
\text { Emergent }\end{array}$ & $\begin{array}{r}35(25.7) \\
101(74.3)\end{array}$ & $\begin{array}{l}22(37.3) \\
37(62.7 \%)\end{array}$ & $\begin{array}{l}13(16.9) \\
64(83.1)\end{array}$ & $<.01 \dagger$ \\
\hline Hypertension & $117(86.0)$ & $53(89.8)$ & $64(83.1)$ & $.26 \dagger$ \\
\hline LVEF & $52.4 \pm 10.5$ & $51.6 \pm 9.2$ & $53.1 \pm 11.6$ & $.47 *$ \\
\hline $\mathrm{Hgb}$ & $12.9 \pm 1.8$ & $12.7 \pm 1.6$ & $13.1 \pm 1.9$ & $.35 *$ \\
\hline Previous CVA & $7(5.1)$ & $2(3.4)$ & $5(6.5)$ & $.70 \ddagger$ \\
\hline $\begin{array}{l}\text { COPD } \\
\text { Mild } \\
\text { Moderate }\end{array}$ & $\begin{array}{r}11(8.1) \\
2(1.5)\end{array}$ & $\begin{array}{c}6(10.2) \\
0\end{array}$ & $\begin{array}{l}5(6.5) \\
2(2.6)\end{array}$ & $.97 \dagger$ \\
\hline Diabetes & $10(7.4)$ & $3(5.1)$ & $7(9.1)$ & $.51 \ddagger$ \\
\hline Previous MI & $17(12.5)$ & $2(3.4)$ & $15(19.5)$ & $<.01 \dagger$ \\
\hline CVD & $9(6.6)$ & $3(5.1)$ & $6(7.9)$ & $.63 \ddagger$ \\
\hline PAD & $13(9.6)$ & $4(6.8)$ & $9(11.7)$ & $.55 \dagger$ \\
\hline $\mathrm{sCr}$ & $1.2(1.0-1.6)$ & $1.2(1.0-1.5)$ & $1.2(0.9-1.6)$ & $.57 *$ \\
\hline Malperfusion or shock & $44(33.6)$ & $17(29.3)$ & $27(37.0)$ & $.35 \dagger$ \\
\hline \multicolumn{5}{|l|}{ Aortic insufficiency } \\
\hline 0 (None) & $14(11.4)$ & $5(9.3)$ & $9(13.0)$ & $.64 \dagger$ \\
\hline 0.5 (Trace) & $4(3.3)$ & $3(5.6)$ & $1(1.5)$ & \\
\hline 1 (Mild) & $12(9.8)$ & $7(13.0)$ & $5(7.3)$ & \\
\hline 2 (Moderate) & $17(13.8)$ & $8(14.8)$ & $9(13.0)$ & \\
\hline 3 (Moderate-severe) & $31(25.2)$ & $13(24.1)$ & $18(26.1)$ & \\
\hline 4 (Severe) & 45 (36.6) & $18(33.3)$ & $27(39.1)$ & \\
\hline
\end{tabular}

Data are presented as number (\% of group total), mean \pm standard deviation, or median (interquartile range). VSRR, Valve-sparing root replacement; ROOT, aortic root replacement with composite valved-conduit; $C A B$, coronary artery bypass; $L V E F$, left ventricular ejection fraction; $H g b$, hemoglobin; $C V A$, cerebrovascular accident; $C O P D$, chronic obstructive pulmonary disease; $M I$, myocardial infarction; $C V D$, cerebrovascular disease; $P A D$, peripheral arterial disease; $s C R$, serum creatinine. *Student $t$ test. $\dagger \chi^{2}$ test. †FFisher exact test.

straight tube grafts, although occasionally the Gelweave Valsalva (Vascutek; Terumo, Ann Arbor, Mich) and Cardioroot (Maquet; Wayne, $\mathrm{NJ})$ grafts were used. For straight grafts, the neoannulus and neosinotubular junctions were plicated with 4-0 braided polyester sutures. The graft was then anchored to the annulus with 3-0 braided polyester horizontal mattress or simple interrupted sutures, and the valve commissures were positioned within the graft for optimal symmetrical leaflet coaptation and were reimplanted using running 4-0 polypropylene sutures starting at the nadir of each cusp. The coronary buttons were then reimplanted, and any necessary cusp repairs were preformed before completing the graft-tograft anastomosis. In general, Teflon felt or xenopericardial strips are avoided in the reconstruction procedure.

For patients in whom the valve anatomy was unsalvageable, conventional root replacement was performed with a valved conduit (ROOT). Mechanical, stented bioprosthetic, or stentless bioprosthetic (Freestyle; Medtronic, Minneapolis, Minn) valves were used at the operating surgeon's discretion on the basis of pertinent patient factors. When available, prefabricated valved conduits were used off-the-shelf; otherwise, an appropriately sized valve was implanted into an appropriately sized Valsalva or Cardioroot graft. As in the VSRR group, the aortic root was dissected down to the annulus after creation of coronary buttons. The valve was excised and the valved conduit graft was secured to the annulus with braided sutures. Coronary buttons were reimplanted and graft-to-graft continuity was established.

\section{Short- and Long-Term Outcomes and Surveillance Imaging}

The primary outcomes of interest were all-cause mortality, need for valve reintervention, aortic reintervention, and degree of AI. Demographic characteristics, perioperative data, and short-term outcomes data were collected from the institutional Society of Thoracic Surgeons database. In addition to standard intraoperative TEE, all patients received transthoracic echocardiogram (TTE) before hospital discharge. VSRR patients were followed prospectively with surveillance TTE at 1, 6, and 12 months and annually thereafter. AI was reported on the basis of a semiquantitative scale as 0 (grade 0$)$, trace $(0.5+)$, mild $(1+)$, moderate $(2+)$, moderatesevere $(3+)$, and severe $(4+)$. When the regurgitant jet was interpreted as between 2 grades, the more severe grade of insufficiency was recorded. 
TABLE 2. Operative variables according to group

\begin{tabular}{|c|c|c|c|c|}
\hline Variable & All $(\mathbf{N}=136)$ & $\operatorname{VSRR}(\mathbf{n}=59)$ & ROOT $(\mathbf{n}=77)$ & $P$ value \\
\hline $\mathrm{CPB}$, minutes & $270.0 \pm 68.4$ & $283.6 \pm 61.3$ & $259.5 \pm 72.0$ & $.04 *$ \\
\hline $\mathrm{XC}$ time, minutes & $212.2 \pm 52.8$ & $238.5 \pm 46.8$ & $191.6 \pm 48.1$ & $<.0001^{*}$ \\
\hline Circulatory arrest time, minutes & $36.3 \pm 15.5$ & $40.1 \pm 18.2$ & $32.9 \pm 11.7$ & $.03^{*}$ \\
\hline $\begin{array}{l}\text { Aortic procedure } \\
\text { Ascending } \\
\text { Hemiarch } \\
\text { Total arch } \\
\text { Elephant trunk }\end{array}$ & $\begin{array}{r}132(97.1) \\
105(77.2) \\
16(11.8) \\
14(10.3)\end{array}$ & $\begin{array}{r}55(93.2) \\
38(64.4) \\
13(22.0) \\
8(13.6)\end{array}$ & $\begin{array}{l}77(100.0) \\
67(87.0) \\
3(3.9) \\
6(7.8)\end{array}$ & $<.01 \dagger$ \\
\hline $\begin{array}{l}\text { Valve type } \\
\text { Mechanical } \\
\text { Stented bioprosthesis } \\
\text { Freestyle }\end{array}$ & $\mathrm{n} / \mathrm{a}$ & $\mathrm{n} / \mathrm{a}$ & $\begin{array}{l}41(53.2) \\
10(13.0) \\
26(33.8)\end{array}$ & $\mathrm{n} / \mathrm{a}$ \\
\hline $\begin{array}{l}\text { Valve repair type } \\
\text { Commissuroplasty } \\
\text { Cusp plication/shortening } \\
\text { Complex } \\
\text { None }\end{array}$ & $\mathrm{n} / \mathrm{a}$ & $\begin{array}{c}1(1.7) \\
5(8.5) \\
3(5.1) \\
50(84.7)\end{array}$ & $\mathrm{n} / \mathrm{a}$ & $\mathrm{n} / \mathrm{a}$ \\
\hline $\begin{array}{l}\text { Additional procedures } \\
\text { CABG } \\
\text { Intraoperative transfusion }\end{array}$ & $\begin{array}{r}27(21.1) \\
133(97.8)\end{array}$ & $\begin{array}{c}9(15.3) \\
59(100.0)\end{array}$ & $\begin{array}{l}18(26.1) \\
74(96.1)\end{array}$ & $\begin{array}{l}.13 \ddagger \\
.26 \S\end{array}$ \\
\hline $\begin{array}{l}\text { Chest closure AI } \\
0 \text { (None) } \\
0.5 \text { (Trace) } \\
1 \text { (Mild) } \\
2 \text { (Moderate) } \\
3 \text { (Moderate-severe) } \\
4 \text { (Severe) }\end{array}$ & $\begin{array}{c}98(82.4) \\
15(12.6) \\
5(4.2) \\
1(0.8) \\
0 \\
0\end{array}$ & $\begin{array}{c}40(75.5) \\
12(22.6) \\
1(1.9) \\
0 \\
0 \\
0\end{array}$ & $\begin{array}{c}58(87.9) \\
3(4.6) \\
4(6.1) \\
1(1.52) \\
0 \\
0\end{array}$ & $<.01 \dagger$ \\
\hline
\end{tabular}

Data are presented as number (\% of group total), or mean \pm standard deviation. VSRR, Valve-sparing root replacement; ROOT, aortic root replacement with composite valved-conduit; $C P B$, cardiopulmonary bypass; $X C$, cross-clamp; n/a, not applicable; $C A B G$, coronary artery bypass grafting; $A I$, aortic insufficiency. $*$ Student $t$ test. $\dagger$ Monte Carlo exact test. $\ddagger \chi^{2}$ test. $\S$ Fisher exact test.

\section{Statistical Analysis}

Descriptive statistics of patient demographic and clinical baseline characteristics were calculated. Continuous variables are reported as the mean \pm standard deviation (or the median and the interquartile range, as appropriate); categorical variables are reported as frequency (percentage). For preoperative, intraoperative, and postoperative comparisons, Student $t$ test (or Mann-Whitney test, as appropriate) was used to compare group means, and $\chi^{2}$ test (or Monte Carlo exact tests, as appropriate) were used to compare group proportions. Overall survival probabilities of VSRR and ROOT groups were visualized using Kaplan-Meier curves. Stratifying on the status of VSRR, competing risk analysis was performed for the outcomes of valve intervention, aortic intervention, and echocardiographic evidence of $\mathrm{AI}>2$, and Gray test for equivalence of the cumulative incidence function was used to compare groups. Hazard ratios for competing risk of death and distal aortic reintervention or aortic valve reintervention were estimated using the subdistribution hazard model. Finally, a composite outcome of valve intervention and echocardiographic evidence of AI $>2$ was used along with mortality. All tests of hypotheses were 2 -sided and conducted at a 0.05 level of significance. All statistical analyses were performed using SAS software version 9.4 (SAS Institute, Cary, NC).

\section{RESULTS}

Preoperative demographic characteristics in each group are shown in Table 1. VSRR patients were significantly younger, with a mean age $43.5 \pm 11.4$ years, compared with $50.4 \pm 13.0$ years for ROOT patients $(P=.001)$. Most patients in both groups were male and had preserved left ventricular function (mean ejection fraction $51.6 \%$ VSRR and 53.1\% ROOT; $P=.47$ ). Preoperative diabetes, previous stroke, cerebrovascular disease, peripheral arterial disease, serum creatinine, and hemoglobin were similar between the groups. In the VSRR group, 17 patients presented with cardiogenic shock or evidence of visceral or limb malperfusion, which was similar to the ROOT group (27 patients). Most patients had $>2+$ AI on the initial intraoperative TEE, and no statistically significant differences between the VSRR and ROOT groups were observed in degree of $\mathrm{AI}$ on presentation.

Surrogate markers of operative complexity were significantly different between groups. Cardiopulmonary bypass time, cross-clamp time, and circulatory arrest time were all longer in the VSRR group (Table 2). Mean cross-clamp time was approximately 50 minutes longer in the VSRR group. Most patients in the ROOT group had a mechanical valve prosthesis implanted. In both groups, most patients received blood products intraoperatively. 
TABLE 3. Short-term postoperative outcomes according to group

\begin{tabular}{|c|c|c|c|c|}
\hline Variable & All $(N=136)$ & $\operatorname{VSRR}(\mathbf{n}=\mathbf{5 9})$ & ROOT $(n=77)$ & $P$ value \\
\hline Stroke & $5(3.7)$ & $1(1.7)$ & $4(5.2)$ & $.39^{*}$ \\
\hline PPM placement & $1(0.7)$ & 0 & $1(1.3)$ & $>.99 *$ \\
\hline Re-explore for bleeding & $18(13.2)$ & $5(8.5)$ & $11(14.3)$ & $.15 \dagger$ \\
\hline Pneumonia & $16(11.8)$ & $5(8.5)$ & $11(14.3)$ & $.30^{\dagger}$ \\
\hline Atrial fibrillation & $37(27.2)$ & $10(16.9)$ & $27(35.1)$ & $.02 \dagger$ \\
\hline Renal failure & $18(13.2)$ & $6(10.2)$ & $12(15.6)$ & $.36 \dagger$ \\
\hline Ventilator time, hours & $23.9(14.0-65.3)$ & $18.4(10.3-41.0)$ & $27.7(16.0-114.7)$ & $.04 \ddagger$ \\
\hline Ventilator $>24 \mathrm{~h}$ & $67(49.3)$ & $25(42.4)$ & $42(54.5)$ & $.16^{\dagger}$ \\
\hline ICU LOS, hours & $83.9(42.8-166.8)$ & $62.0(39.5-116.7)$ & $87.5(45.6-231.7)$ & $.03 \ddagger$ \\
\hline LOS, d & $8(6-15)$ & $8(5-10)$ & $10(6-17)$ & $.049 \ddagger$ \\
\hline 30-Day mortality & $12(8.8)$ & $2(3.4)$ & $10(13.0)$ & $.05 \dagger$ \\
\hline Discharge to home & $107(84.3)$ & $52(91.2)$ & $55(78.6)$ & $.05 \dagger$ \\
\hline
\end{tabular}

Data are presented as number (\% of group total), or median (interquartile range). VSRR, Valve-sparing root replacement; ROOT, aortic root replacement with composite valved-conduit; $P P M$, permanent pacemaker; $I C U$, intensive care unit; $L O S$, length of stay. *Fisher exact test. $\dagger \chi^{2}$ test. $\ddagger$ Mann-Whitney test.

The incidence of coronary artery bypass because of either destruction of the coronary ostium by the dissection process or for coronary malperfusion as a result of button malalignment was similar between groups.

Because $82 \%$ of the VSRR procedures were performed by the 2 primary aortic surgeons in our institution (E.P.C. and B.G.L.), the incidence of extended arch reconstruction was higher in the VSRR group (VSRR $22.0 \%$ vs ROOT $3.9 \% ; P=.001)$. Four patients in the entire group presented with isolated root dissections and did not require ascending or arch replacement. In the VSRR group, 9 patients (15.3\%) required valve repair consisting of either commissuroplasty $(\mathrm{n}=1)$, cusp free margin plication/shortening $(\mathrm{n}=5)$, or a combination $(\mathrm{n}=3)$. Any patient in the VSRR group who had $>1+$ AI upon weaning from bypass underwent repeat cross-clamping and attempt at further valve repair. Thus, AI on chest closure TEE was 0 to trace $(0.5+)$ in nearly all patients. At chest closure, there was a single patient in the VSRR group with $1+\mathrm{AI}$ and 5 patients in the ROOT group with $>1+$ AI.

Short-term postoperative outcomes were similar among the groups with regard to stroke, complete heart block requiring pacemaker implantation, renal failure requiring dialysis, and atrial fibrillation (Table 3). VSRR patients had significantly shorter ventilator times, and intensive care unit and hospital length of stay compared with ROOT patients. Thirty-day mortality was lower in the VSRR group, with only 2 deaths $(3.4 \%)$ compared with 10 in the ROOT group $(13.0 \% ; P=.05)$. Among the VSRR group, 1 patient had a history of cocaine abuse and died of postcardiotomy right ventricular failure, and the second death was a result of a large cerebellar infarct and subsequent massive cerebral edema prompting family members to withdraw life-sustaining measures.
Follow-up (survival and echocardiographic) in patients surviving longer than 30 days was complete in $89.5 \%$ (51/57) of VSRR patients and 59.7\% (40/67) of ROOT patients. All-cause mortality was significantly lower in the VSRR group compared with the ROOT group $(P=.002$; Figure 1). One-year, 5-year, and 9-year survival in the VSRR group was $94.7 \%, 92 \%$, and $92 \%$, respectively, compared with $80.3 \%, 73.3 \%$, and $58.8 \%$, respectively, in the ROOT group. Hazard ratio comparing hazard of death between VSRR and ROOT was 0.194 (95\% confidence interval $[\mathrm{CI}], 0.06-0.60 ; P=.004)$.

The need for aortic reintervention in both groups was similar, with 1-year, 5-year, and 9-year incidence of

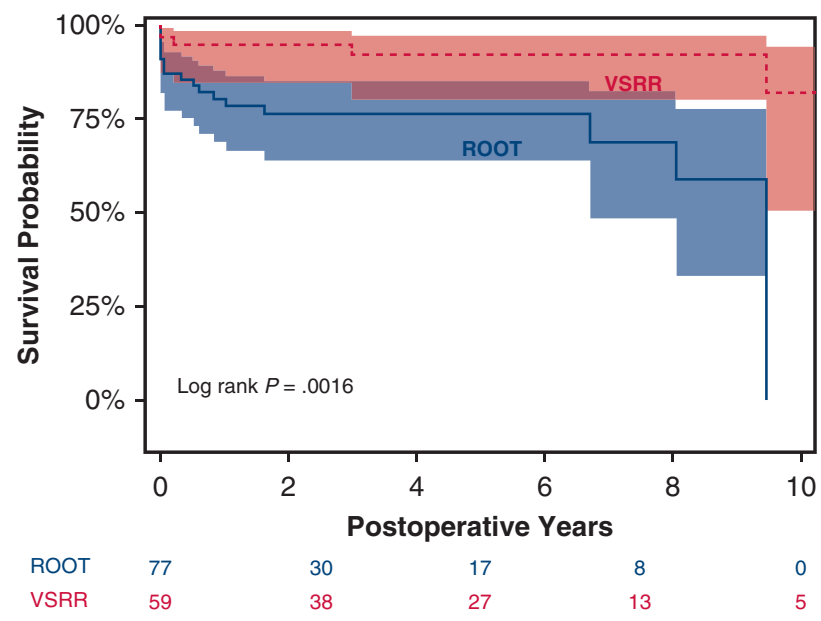

FIGURE 1. Kaplan-Meier all-cause survival analysis of valve-sparing root replacement (VSRR; red) and aortic root replacement with composite valved-conduit (ROOT; blue) patients. Shaded areas indicate $95 \%$ confidence intervals, with numbers at the bottom of the figure showing numbers at risk for the given time points. VSRR versus ROOT hazard ratio for death, 0.194 (95\% confidence interval, 0.063-0.596); $P=.004$. 

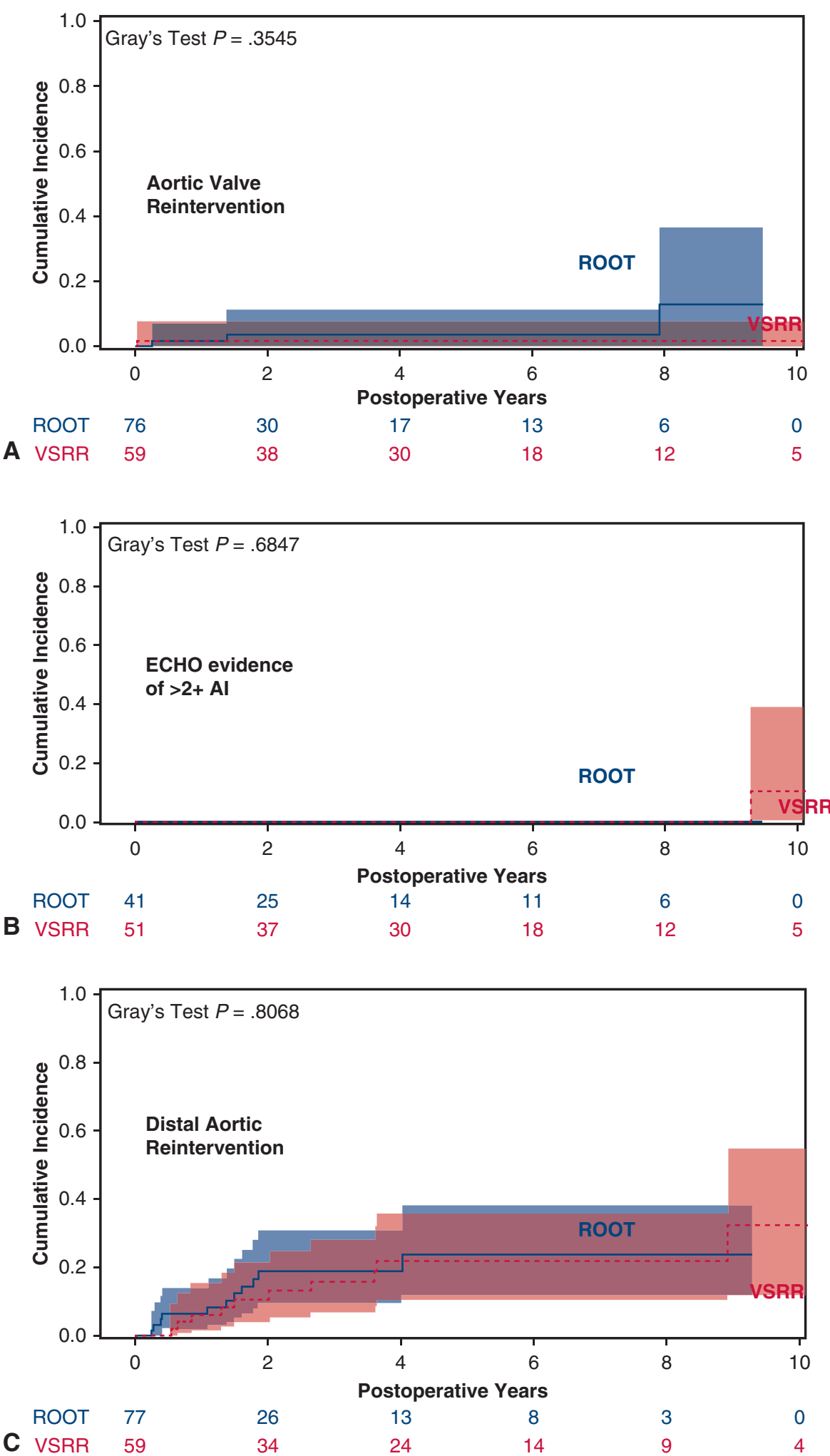

FIGURE 2. Cumulative incidence of aortic valve reintervention (A), echocardiographic evidence of $>2+$ aortic insufficiency (AI; B), and distal aortic reintervention (C) in valve-sparing root replacement (VSRR; red) and aortic root replacement with composite valved-conduit (ROOT; blue) groups. Shaded areas indicate $95 \%$ confidence intervals, with numbers at the bottom of the figure showing numbers at risk for the given time points. ECHO, Echocardiographic. 
$6.2 \%, 21.8 \%$, and $32.3 \%$, respectively, in the VSRR group and $6.3 \%, 23.8 \%$, and $23.8 \%$, respectively, in the ROOT group $(P=.81$; Figure $2, C)$. In the VSRR group, all aortic reinterventions $(\mathrm{n}=10)$ were distal $(1$ endovascular and 9 open thoracoabdominal aortic replacements) and in the ROOT group, aortic reinterventions were proximal $(\mathrm{n}=5 ; 4$ redo root/ascending/hemiarch aortic replacements and 1 repair of a coronary button pseudoaneurysm) and distal $(\mathrm{n}=6 ; 1$ total arch replacement and 5 open thoracoabdominal aortic replacements). VSRR versus ROOT hazard ratio for death and aortic valve reintervention was $0.98(95 \% \mathrm{CI}, 0.43-2.26 ; P=.9)$.

Cumulative incidence of valve reintervention was low in both groups and not statistically different (Figure 2, A). In the VSRR group, only 1 patient required valve replacement because of the development of severe AI. In the ROOT group, 1-year, 5-year, and 9-year valve reintervention incidence was $1.55 \%, 3.62 \%$, and $12.93 \%$, respectively (mechanical: $\mathrm{n}=3$, stented bioprosthetic: $\mathrm{n}=1$, stentless bioprosthetic: $\mathrm{n}=0$ ). Redo valve replacement was required in the ROOT group because of endocarditis $(n=1)$ and severe prosthetic valve stenosis or patient-prosthesis mismatch $(\mathrm{n}=3)$. VSRR versus ROOT hazard ratio for death and aortic valve reintervention was $0.39(95 \% \mathrm{CI}$, 0.04-3.96; $P=.43$ ).

Table 4 shows the preoperative and follow-up echocardiographic findings in VSRR patients. At a mean follow-up of $57.7 \pm 42.1$ months (range, 0.2-137 months), only 1 patient had $>2+$ AI. Degree of valve insufficiency in individual VSRR and ROOT patients at each time point for which we have echocardiographic data (preoperative, immediate postoperative, first follow-up, and last follow-up) is shown in Figure E1. Although the goal was for the first postoperative TTE to be performed at 1 month, the mean time was $5.8 \pm 9.6$ months and $8.7 \pm 18.5$ months in the VSRR and ROOT groups, respectively. The mean time to last follow-up echocardiography was $58.2 \pm 41.0$ months and $34.4 \pm 32.1$ months in the VSRR and ROOT groups, respectively.

As for death and valve reintervention or surveillance echocardiographic evidence of $>2+\mathrm{AI}$, VSRR patients had markedly better event-free survival compared with ROOT patients. At 5 years, event-free survival in the ROOT group was $72 \%$ whereas it was $90 \%$ in the VSRR group (Figure 3).

\section{DISCUSSION}

Acute TAAD is a surgical emergency that carries a $20 \%$ risk of mortality in contemporary series. Throughout the literature, experts have advocated for a range of treatment options, including ascending aortic and hemiarch replacement, aggressive arch reconstruction, and more recent hybrid approaches including antegrade stent graft deployment into the descending aorta at the time of
TABLE 4. Echocardiographic outcomes in VSRR patients

\begin{tabular}{lccc}
\hline \multicolumn{1}{c}{ Degree of AI } & $\begin{array}{c}\text { Preoperative } \\
(\mathbf{n}=\mathbf{5 4})\end{array}$ & $\begin{array}{c}\text { Postoperative } \\
(\mathbf{n}=\mathbf{5 3})\end{array}$ & $\begin{array}{c}\text { Last follow-up } \\
(\mathbf{n}=\mathbf{5 1})\end{array}$ \\
\hline None & 5 & 40 & 28 \\
Trace $(0.5+)$ & 3 & 12 & 13 \\
Mild (1+) & 7 & 1 & 9 \\
Moderate (2+) & 8 & 0 & 0 \\
Moderate-severe (3+) & 13 & 0 & 1 \\
Severe (4+) & 18 & 0 & 0 \\
\hline
\end{tabular}

$A I$, Aortic insufficiency.

hypothermic circulatory arrest via the open arch. With respect to aortic root pathology and involvement, the primary surgical options include limited valve resuspension or aortic root replacement.

Although VSRR is a well established technique for root replacement in young patients who present with elective aortic root pathology (chronic dissection or aneurysm), it is only selectively performed in the setting of TAAD with root pathology. Limited studies exist on outcomes for VSRR in TAAD compared with those of the standard Bentall, and our group has previously examined the mid-term survival outcomes and valve durability in this challenging patient population. ${ }^{12,20,21}$ In the present study, we show that VSRR can be performed in the acute setting with similar perioperative outcomes and excellent long-term durability compared with Bentall root replacement.

The primary concerns of performing VSRR in this emergent clinical setting are the safety and durability of a more complex operation and the risk of late valvular dysfunction secondary to AI. The additional time required to evaluate valve function and adequately perform VSRR might not be tolerated in acute dissection and as such should only be undertaken by surgeons with extensive experience in VSRR. Despite longer operative, cardiopulmonary bypass, and myocardial ischemia times in the VSRR patients, incidence of perioperative renal failure, stroke, and myocardial infarction was low or equivalent to the ROOT group. This might be because of the younger age of the VSRR patients (43.5 years vs 50.4 years) who are less likely to have concomitant atherosclerotic coronary artery, cerebrovascular, and peripheral vascular disease. However, the younger patients who present with TAAD gain the most benefit from VSRR, because patients younger than 55 years would likely receive a mechanical valved-conduit, and therefore carry the lifelong burden of anticoagulation and its attendant risks.

Although our data show a survival advantage to VSRR compared with ROOT in TAAD with excellent durability, there are still groups that advocate for a conservative strategy. Yang and colleagues from the Michigan group examined patients with acute TAAD requiring root 

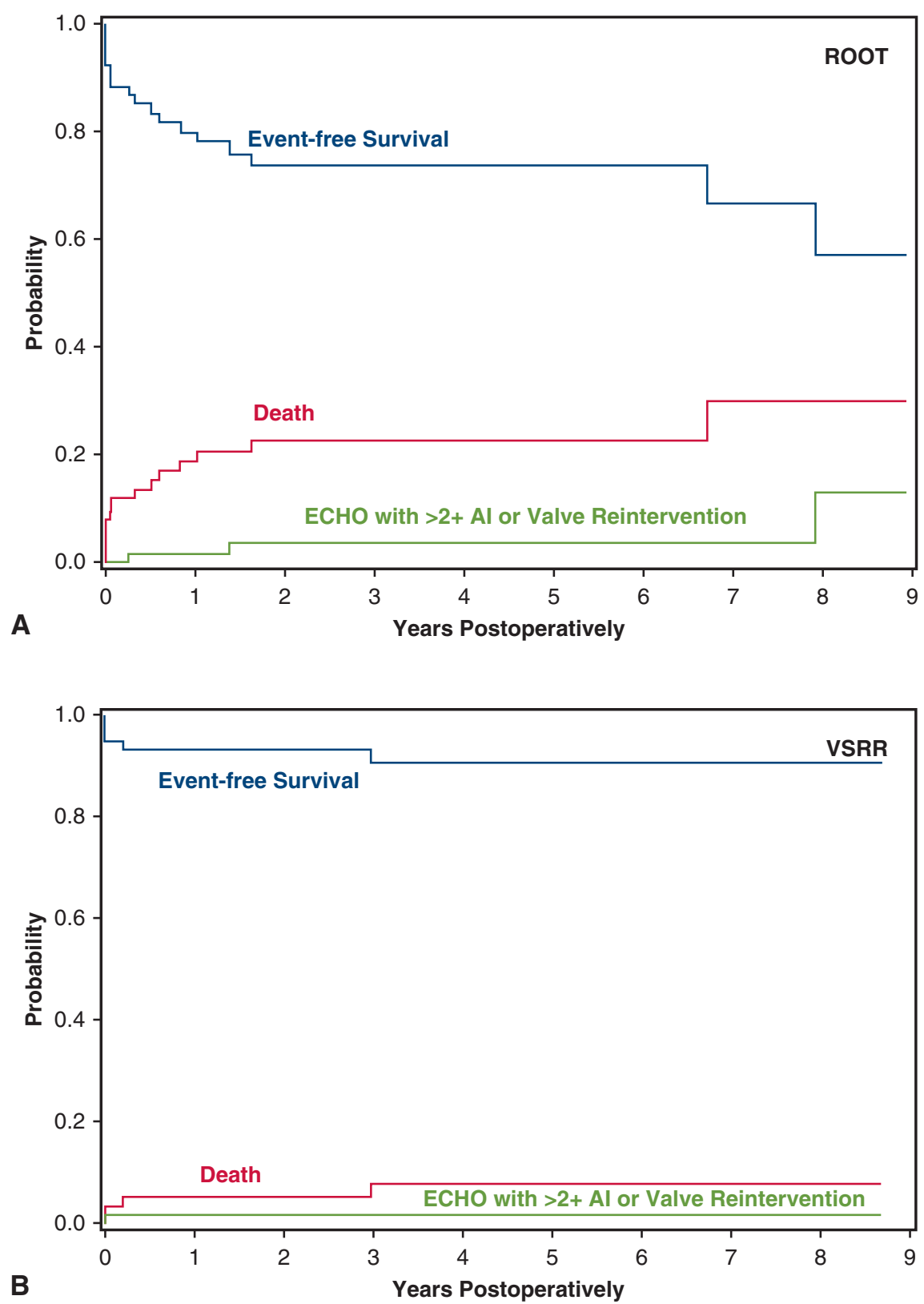

FIGURE 3. Competing risk analysis for risk of death (red line), echocardiographic evidence of $>2+$ aortic insufficiency $(A I)$ or valve reintervention (green line), and event-free survival (blue line) in aortic root replacement with composite valved-conduit (ROOT; A) and valve-sparing root replacement $(V S R R ; \mathrm{B})$ patient groups. ECHO, Echocardiographic.

replacement, root repair without Teflon reinforcement or bioglue, and patients with no root procedure needed. ${ }^{9}$ They showed that at 5 years, no patients had evidence of root aneurysmal degeneration or need for valve reintervention. Furthermore, similar to the findings of the current study, root repair patients had improved overall survival compared with Bentall patients. Chiu and colleagues from Stanford compared valve repair with Bentall (including 3 patients who underwent VSRR) in acute TAAD and showed equivalent risk-adjusted mortality, but an $11.8 \%$ risk of reoperation in the repair group at 10 years compared with $0 \%$ in the Bentall group. ${ }^{22}$ Because of this risk for late reoperation, we instituted an aggressive approach in carefully selected patients with normal cusps, consisting of resection of all dissected root tissue and proceeding with VSRR. In our patients, this provides a durable result with equivalent perioperative morbidity compared with Bentall.

Ultimately, the test of VSRR or Bentall durability is long-term valve function measured using surveillance 
echocardiography or need for valve reintervention. In our patient group, VSRR provided excellent valve durability at mean follow-up of 57.7 months (range, 0.2-137.2 months). Only 1 patient required valve replacement after VSRR. This patient developed severe AI early in the postoperative period and was taken back to the operating room for valve replacement. This is the only failure in the VSRR group at the current time. Perhaps even more important and suggestive of durability is that valve function according to TTE was excellent. Only 1 patient had 3+ AI with no evidence of ventricular dysfunction, and all other patients with long-term follow-up $(51 / 59 ; 86.4 \%)$ had $<2+$ AI.

Early in our series, VSRR was not performed on patients who were hemodynamically unstable or who had evidence of visceral or limb malperfusion. As we have become more comfortable with our operative technique and surgical management, we have narrowed our exclusion criteria. Reflective of this change in practice, 17 of the VSRR patients in this study $(29.3 \%)$ presented with cardiogenic shock or malperfusion, a number similar to those in the ROOT group.

There are several limitations of the current study. First, it is difficult to ignore the effect of selection bias, because of the retrospective and nonrandomized study design. Although the basic demographic characteristics are similar between groups, the significant difference in mortality is likely reflective of preoperative differences. The relatively small samples sizes precluded the use of regression adjustment. Second, the relatively limited follow-up $(52 \%)$ in the ROOT group introduces observation bias that cannot be accounted for. Since many of these patients presented as transfers from distant rural medical centers and there was no perceived reason to follow them long-term postoperatively (they presumably have stable, durable prosthetic valve replacements), they were lost to follow-up. Third, most of the VSRR operations were performed by 2 surgeons in our institution who have particular expertise in aortic surgery; it is difficult to separate the effect of surgeon from that of surgical procedure. VSRR and ROOT and their subsequent outcomes would not translate to the average practitioner encountering TAAD with root involvement in a community practice.

\section{CONCLUSIONS}

The data from this report support the concept of proceeding with aggressive surgical treatment of TAAD with aortic root pathology and preserved leaflet anatomy using the David V VSRR approach in appropriately selected patients. Our results show excellent long-term survival as well as superior valve competence and durability, with no need for valve replacement because of long-term degradation and perioperative morbidity and mortality that is similar to that in Bentall root replacements. It must be emphasized that this success might be more reflective of a highly-selected patient population as well as a center and surgeons who have extensive expertise in caring for complex patients with acute TAAD and root pathology. We caution against the performance of VSRR in acute TAAD for the novice practitioner, because the primary goal remains operative survival. If VSRR is performed, a strict surveillance protocol must be adhered to, because conclusive data do not exist showing superior valve durability with VSRR compared with ROOT in the emergent setting. Further studies are necessary to elucidate which patient populations might be the greatest beneficiary of native aortic valve preservation.

\section{Webcast}

You can watch a Webcast of this AATS meeting presentation by going to: https://aats.blob.core.windows.net/media/ 18AO/26-br-1000-chen-v2.mp4.

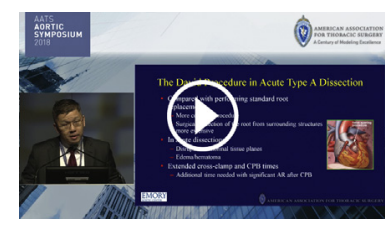

\section{Conflict of Interest Statement}

Authors have nothing to disclose with regard to commercial support.

\section{References}

1. Daily PO, Trueblood HW, Stinson EB, Wuerflein RD, Shumway NE. Management of acute aortic dissections. Ann Thorac Surg. 1970;10:237-47.

2. Attar S, Fardin R, Ayella R, McLaughlin JS. Medical vs surgical treatment of acute dissecting aneurysms. Arch Surg. 1971;103:568-73.

3. Pape LA, Awais M, Woznicki EM, Suzuki T, Trimarchi S, Evangelista A, et al. Presentation, diagnosis, and outcomes of acute aortic dissection: 17-year trends from the International Registry of Acute Aortic Dissection. J Am Coll Cardiol. 2015;66:350-8.

4. Bavaria JE, Pochettino A, Brinster DR, Gorman RC, McGarvey ML, Gorman JH, et al. New paradigms and improved results for the surgical treatment of acute type A dissection. Ann Surg. 2001;234:336-42; discussion: 342-3.

5. Comas GM, Leshnower BG, Halkos ME, Thourani VH, Puskas JD, Guyton RA, et al. Acute type a dissection: impact of antegrade cerebral perfusion under moderate hypothermia. Ann Thorac Surg. 2013;96:2135-41.

6. Halstead JC, Spielvogel D, Meier DM, Rinke S, Bodian C, Malekian R, et al. Composite aortic root replacement in acute type A dissection: time to rethink the indications? Eur J Cardiothorac Surg. 2005;27:626-32; discussion: 632-3.

7. Chikwe J, Cavallaro P, Itagaki S, Seigerman M, Diluozzo G, Adams DH National outcomes in acute aortic dissection: influence of surgeon and institutional volume on operative mortality. Ann Thorac Surg. 2013;95:1563-9.

8. Geirsson A, Bavaria JE, Swarr D, Keane MG, Woo YJ, Szeto WY, et al. Fate of the residual distal and proximal aorta after acute type a dissection repair using a contemporary surgical reconstruction algorithm. Ann Thorac Surg. 2007;84: 1955-64; discussion: 1955-64.

9. Yang B, Malik A, Waidley V, Kleeman KC, Wu X, Norton EL, et al. Short-term outcomes of a simple and effective approach to aortic root and arch repair in acute type A aortic dissection. J Thorac Cardiovasc Surg. 2018;155:1360-70.e1361.

10. David TE. The aortic valve-sparing operation. J Thorac Cardiovasc Surg. 2011; $141: 613-5$. 
11. Sarsam MA, Yacoub M. Remodeling of the aortic valve anulus. J Thorac Cardiovasc Surg. 1993;105:435-8.

12. Leshnower BG, Myung RJ, McPherson L, Chen EP. Midterm results of David V valve-sparing aortic root replacement in acute type A aortic dissection. Ann Thorac Surg. 2015;99:795-800; discussion: 800-1.

13. Yang B, Patel HJ, Sorek C, Hornsby WE, Wu X, Ward S, et al. Sixteen-year experience of David and Bentall procedures in acute type A aortic dissection. Ann Thorac Surg. 2018;105:779-84.

14. Kunihara T, Neumann N, Kriechbaum SD, Aicher D, Schafers HJ. Aortic root remodeling leads to good valve stability in acute aortic dissection and preexistent root dilatation. J Thorac Cardiovasc Surg. 2016;152:430-6.e431.

15. Stephens EH, Borger MA. Getting to the root of the matter: management of the aortic root in type A aortic dissection. Eur J Cardiothorac Surg. 2016;50:230-1.

16. Kallenbach K, Oelze T, Salcher R, Hagl C, Karck M, Leyh RG, et al. Evolving strategies for treatment of acute aortic dissection type A. Circulation. 2004; 110:II243-9.

17. Hiratzka LF, Bakris GL, Beckman JA, Bersin RM, Carr VF, Casey Jr DE, et al, 2010 ACCF/AHA/AATS/ACR/ASA/SCA/SCAI/SIR/STS/SVM guidelines for the diagnosis and management of patients with thoracic aortic disease: a report of the American College of Cardiology Foundation/American Heart Association Task Force on Practice Guidelines, American Association for Thoracic Surgery, American College of Radiology, American Stroke Association, Society of Cardiovascular Anesthesiologists, Society for Cardiovascular
Angiography and Interventions, Society of Interventional Radiology, Society of Thoracic Surgeons, and Society for Vascular Medicine. Circulation. 2010; 121:e266-369.

18. Leshnower BG, Myung RJ, Kilgo PD, Vassiliades TA, Vega JD, Thourani VH et al. Moderate hypothermia and unilateral selective antegrade cerebral perfusion: a contemporary cerebral protection strategy for aortic arch surgery. Ann Thorac Surg. 2010;90:547-54.

19. Leshnower BG, Guyton RA, Myung RJ, Puskas JD, Kilgo PD, McPherson L, et al. Expanding the indications for the David V aortic root replacement: early results. J Thorac Cardiovasc Surg. 2012;143:879-84.

20. Erasmi AW, Stierle U, Bechtel JF, Schmidtke C, Sievers HH, Kraatz EG. Up to 7 years' experience with valve-sparing aortic root remodeling/reimplantation for acute type A dissection. Ann Thorac Surg. 2003;76:99-104.

21. Subramanian S, Leontyev S, Borger MA, Trommer C, Misfeld M, Mohr FW Valve-sparing root reconstruction does not compromise survival in acute type A aortic dissection. Ann Thorac Surg. 2012;94:1230-4.

22. Chiu P, Trojan J, Tsou S, Goldstone AB, Woo YJ, Fischbein MP. Limited roo repair in acute type A aortic dissection is safe but results in increased risk of reoperation. J Thorac Cardiovasc Surg. 2018;155:1-7.e1.

Key Words: type A aortic dissection, valve-sparing root replacement, David V 


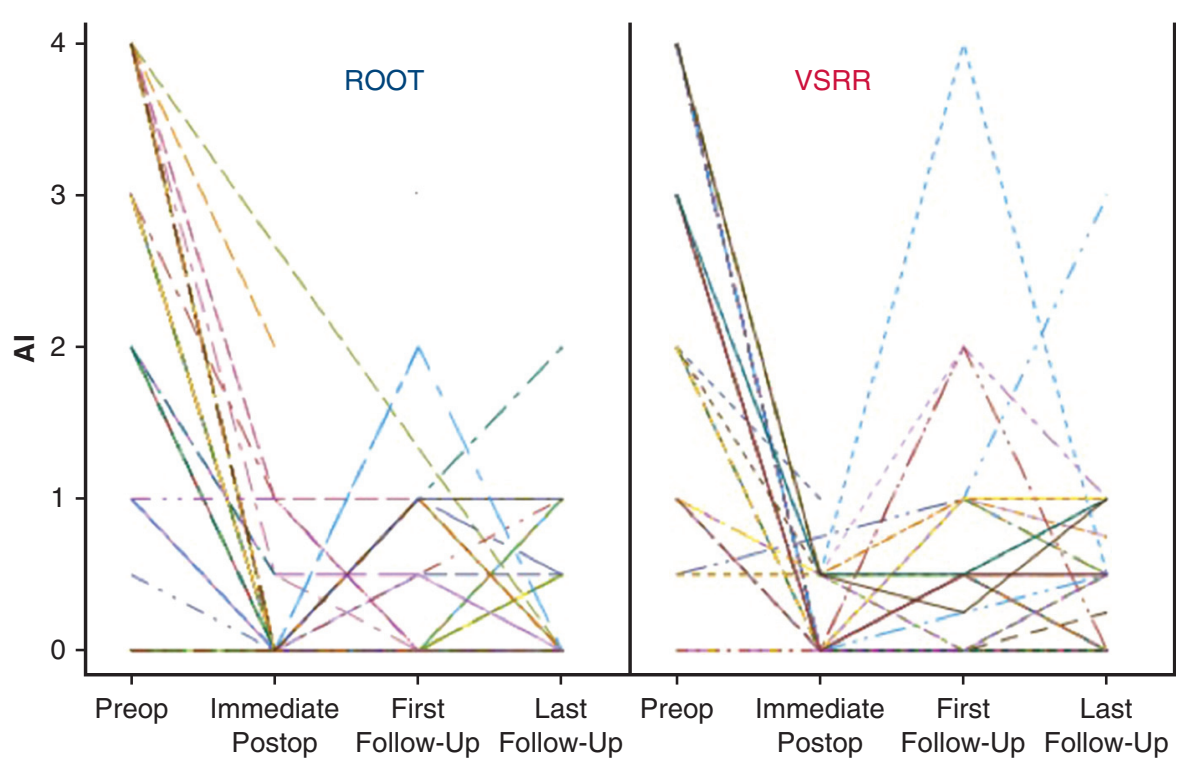

FIGURE E1. Echocardiographic evidence of aortic insufficiency $(A I)$ in each patient at the time points listed in aortic root replacement with composite valved-conduit (ROOT; left panel) and valve-sparing root replacement (VSRR; right panel) patients. Each line represents a single patient. Preop, Preoperative; Postop, postoperative. 